\title{
Hepatocellular Carcinoma in Children and Adolescents: Clinical Characteristics and Treatment
}

\author{
Juncheng Wang ${ }^{1}$ Yize Mao ${ }^{1}$ Yongcheng Liu ${ }^{1,2} \cdot$ Zhenxin Chen $^{1} \cdot$ Minshan Chen ${ }^{1}$. \\ Xiangming $\mathrm{Lao}^{1} \cdot$ Shengping $\mathrm{Li}^{1}$
}

Received: 10 February 2017 / Accepted: 30 March 2017 / Published online: 10 April 2017

(C) 2017 The Author(s). This article is published with open access at Springerlink.com

\begin{abstract}
Background Hepatocellular carcinoma (HCC) occurs rarely in children and adolescents (C\&A), and its clinical characteristics, prognostic factors, and treatment were rarely explored.

Methods This retrospective study focused on 65 HCC patients aged $\leq 20$ years from August 1994 to August 2012. Cox regression models and Kaplan-Meier curves were used to investigate prognostic factors and compare overall survival (OS), respectively. Results We found $61.5 \%$ of patients to have multiple tumors, $30.8 \%$ to have portal vein tumor thrombus, and $16.9 \%$ to have distant metastasis. Diameter of tumors was $10.2 \pm 4.1 \mathrm{~cm}$. OS at 5 years was $15.8 \%$. Multivariate analyses showed initial treatment $(P<0.001)$ to be a predictor for OS. For moderate-stage HCC, the median OS of patients who underwent resection was longer than that of patients who underwent transarterial chemoembolization (TACE) or supportive treatment (ST) $(P<0.001)$. For advanced-stage HCC, the median OS of patients who underwent TACE was longer than that of patients who underwent ST $(P=0.045)$.

Conclusions $\mathrm{HCC}$ in C\&A tends to be more advanced than that in adults, and resection remains the mainstay of treatment for those patients. Moreover, compared with ST, TACE may benefit C\&A with moderate- and advanced-stage HCC, which needs further study.
\end{abstract}

Keywords Hepatocellular carcinoma $\cdot$ Children and adolescents $\cdot$ Prognosis $\cdot$ Resection $\cdot$ Transarterial chemoembolization

Juncheng Wang and Yize Mao contributed equally to this work.

Electronic supplementary material The online version of this article (doi:10.1007/s11605-017-3420-3) contains supplementary material, which is available to authorized users.

Xiangming Lao

laoxm@sysucc.org.cn

Shengping Li

lishp@sysucc.org.cn

1 Department of Hepatobiliary Oncology, State Key Laboratory of Oncology in South China; Collaborative Innovation Center for Cancer Medicine, Sun Yat-sen University Cancer Center, No. 651 Dongfeng Road East, Guangzhou 510060, China

2 Department of Surgical Oncology, Sir Run Run Shaw Hospital, Zhejiang University School of Medicine, Hangzhou 310020, China

\section{Introduction}

Liver cancer is the second most common cause of cancerrelated deaths worldwide, and there are approximately 850,000 new cases per year worldwide. ${ }^{1,2}$ Hepatocellular carcinoma (HCC) is the most common type of hepatic malignancy, but only $0.5-1 \%$ of those aged $\leq 20$ years suffer from HCC. $^{3}$

Infection by the hepatitis B virus (HBV) is endemic in China. The incidence of HCC in children and adolescents $(\mathrm{C} \& \mathrm{~A})$ is higher than that for hepatoblastoma, a pattern that is different from that reported in Western countries. ${ }^{4,5}$ Unlike HCC in adults, which commonly arises in the setting of prolonged chronic hepatitis and cirrhosis, ${ }^{6}$ tumors in C\&A have been observed with $\mathrm{HBV}$ infection acquired perinatally or due to inherited metabolic disorders. ${ }^{7,8}$ Moreover, at the time of diagnosis, HCC in C\&A is commonly associated with (i) huge hepatomas, (ii) tumor thrombus in the portal vein, and (iii) distant metastasis. ${ }^{7,9}$ Taken together, such reports suggest that HCC in C\&A may be different to that observed in adults. ${ }^{4,8,10}$ 
Hence, discovering the prognostic factors of $\mathrm{HCC}$ in $\mathrm{C} \& \mathrm{~A}$ may help to improve the diagnosis and treatment of HCC.

Even though HCC in C\&A exhibits a more malignant tendency, treatment guidelines are lacking. Resection is considered to be the mainstay of curative therapy for long-term survival of C\&A with HCC. ${ }^{3,11-13}$ Nevertheless, the efficiency of transarterial chemoembolization (TACE), which is the established treatment for unresectable HCC in adults, ${ }^{14-16}$ for C\&A with HCC is controversial. ${ }^{3}$ More specifically, although promising, experience with TACE in C\&A with HCC is limited, with only sporadic reports in the literature. . $^{3,10}$ Moreover, most of those studies have suggested that TACE may have minimal effects on survival, ${ }^{4,17}$ and only one study showed positive effects in inducing resection of $\mathrm{HCC}$ in C\&A. ${ }^{18}$ As a result, the role of TACE for HCC in C\&A is still unclear.

In the present study, we analyzed (retrospectively) the clinical and pathologic characteristics of HCC in C\&A and evaluated prognostic factors that may help predict survival. Moreover, we compared the outcome of HCC in C\&A who underwent different types of treatment to provide evidence for future therapy.

\section{Patients and Methods}

\section{Patients}

This retrospective study was approved by the Institutional Review Board of Sun Yat-sen University Cancer Center (Guangzhou, China).

From 15 August 1994 to 15 August 2012, 72 patients aged $\leq 20$ years were diagnosed with HCC by histological examination or at least two coincidental imaging techniques associated with increased alpha-fetoprotein (AFP) level in our Department of Hepatobiliary Oncology. Patients lost to follow-up $<1$ month after diagnosis $(n=6)$ or those who did not have sufficient clinical data $(n=1)$ were excluded, thereby leaving 65 patients to form the study cohort.

\section{Follow-Up}

The follow-up program for patients was every 2-3 months for the first postoperative year and 3-6 months thereafter. "Overall survival" (OS) was defined as the interval (in months) from the date of diagnosis to the date of death. Follow-up ended on 1 August 2016.

\section{Collection of Clinical Data}

All clinicopathologic data (age, sex, tumor number, tumor size, distant metastasis, portal vein tumor thrombus, TNM stage) were retrieved from the medical records of Sun Yat- sen University Cancer Center. Laboratory data (HBV infection; levels of AFP, alanine aminotransferase [ALT], aspartate aminotransferase [AST], albumin [ALB], total bilirubin [TBIL]) before surgery were obtained. Tumor stage was determined according to the 7 th TNM staging system established by the Union for International Cancer Control and the American Joint Committee on Cancer. ${ }^{19}$

\section{Statistical Analyses}

For continuous variables, data were expressed as mean \pm standard deviation and were compared using Student's $t$ test (twosided). The Cox proportional hazards model was used for univariate and multivariate analyses. Clinical endpoints were calculated using the Kaplan-Meier method with the logrank test. Analyses were carried out using the SPSS software program (version 20.0; IBM Corporation, Armonk, NY, USA). $P<0.05$ (two-tailed test) was considered significant.

\section{Results}

\section{Survival and Characteristics of Patients}

Median follow-up was 9.1 (range, 1.2-110.2) months. Survival at 1, 3, and 5 years was $50.1,27.5$, and $15.8 \%$, respectively.

Sixty-five patients (52 males, 13 females) with a median age of 16.8 (range, 8-20) years were evaluated (Table 1). Also, $81.5 \%(53 / 65)$ of patients had HBV infection, $61.5 \%$ patients had multiple tumors, $16.9 \%$ had distant metastasis, and $30.8 \%$ had portal vein tumor thrombus. Diameter of tumors was $10.2 \pm 4.1 \mathrm{~cm}$, and $90.8 \%$ of patients were AFPpositive.

\section{TNM Categorization}

According to the survival curves, we categorized TNM stage into three subgroups (Fig. 1): stage I was "early," stages II/ IIIA were "moderate," and stages IIIB/IV were "advanced."

\section{Univariate and Multivariate Analyses for OS in HCC Patients}

Univariate and multivariate analyses were undertaken to explore the prognostic factors of HCC patients (Table 2, Fig. 2). Results of the Cox regression hazards model for predictors of OS are shown in Table 2.

Univariate analyses showed that TNM stage (moderate stage vs. early stage: HR $2.420,95 \%$ confidence interval [CI] 0.835-7.014; advanced stage vs. early stage: HR 7.479, 95\% CI 2.503-22.342, $P<0.001$ ), initial treatment (TACE vs. 
Table 1 Baseline characteristics of C\&A patients with hepatocellular carcinoma (HCC)

\begin{tabular}{|c|c|}
\hline \multicolumn{2}{|l|}{ Variable } \\
\hline Age & $17(8-20)$ \\
\hline \multicolumn{2}{|l|}{ Sex } \\
\hline Female & $13(20 \%)$ \\
\hline Male & $52(80 \%)$ \\
\hline \multicolumn{2}{|l|}{ HBV infection } \\
\hline No & $12(18.5 \%)$ \\
\hline Yes & $53(81.5 \%)$ \\
\hline ALT (U/L) & $64.5 \pm 81.6$ \\
\hline AST (U/L) & $94.3 \pm 130.6$ \\
\hline $\operatorname{ALB}(g / L)$ & $42.9 \pm 5.2$ \\
\hline TBIL $(\mu \mathrm{mol} / \mathrm{L})$ & $22.4 \pm 25.4$ \\
\hline Tumor diameter $(\mathrm{cm})$ & $10.2 \pm 4.1$ \\
\hline \multicolumn{2}{|l|}{ AFP (ng/mL) } \\
\hline$\leq 25$ & $6(9.2 \%)$ \\
\hline$>25$ & $59(90.8 \%)$ \\
\hline \multicolumn{2}{|l|}{ Tumor number } \\
\hline Solitary & $25(38.5 \%)$ \\
\hline Multiple & $40(61.5 \%)$ \\
\hline \multicolumn{2}{|l|}{ Distant metastasis } \\
\hline No & $54(83.1 \%)$ \\
\hline Yes & $11(16.9 \%)$ \\
\hline \multicolumn{2}{|c|}{ Portal vein tumor thrombus } \\
\hline No & $45(69.2 \%)$ \\
\hline Yes & $20(30.8 \%)$ \\
\hline \multicolumn{2}{|l|}{ TNM stage } \\
\hline I & $9(13.8 \%)$ \\
\hline II & $8(12.3 \%)$ \\
\hline IIIA & $22(33.8 \%)$ \\
\hline IIIB & $14(21.5 \%)$ \\
\hline IVA & $1(1.5 \%)$ \\
\hline IVB & $11(16.9 \%)$ \\
\hline \multicolumn{2}{|l|}{ Initial treatment } \\
\hline ST & $16(24.6 \%)$ \\
\hline TACE & $23(35.4 \%)$ \\
\hline Resection & $26(40 \%)$ \\
\hline
\end{tabular}

$H B V$ hepatitis B virus, $A L T$ alanine aminotransferase, $A S T$ aspartate transaminase, $A L B$ albumin, TBIL total bilirubin, $A F P$ alpha-fetoprotein, $T N M$ tumor-node-metastasis, $S T$ supportive treatment, TACE transcatheter arterial chemoembolization supportive treatment [ST]: HR 0.298, 95\% CI 0.150-0.592; resection vs. ST: HR $0.105,95 \%$ CI $0.048-0.226, P<0.001)$, metastasis (HR 2.360, 95\% CI 1.156-4.815, $P=0.015$ ), portal vein tumor thrombus (HR 2.725, 95\% CI 1.484-5.004, $P=0.001)$, TBIL level (HR 1.947, 95\% CI 1.094-3.465, $P=0.021$ ), and AST level (HR 2.365, 95\% CI 1.287-4.346, $P=0.004)$ were associated with OS. Multivariate analyses showed only initial treatment allocation (TACE vs. ST: HR

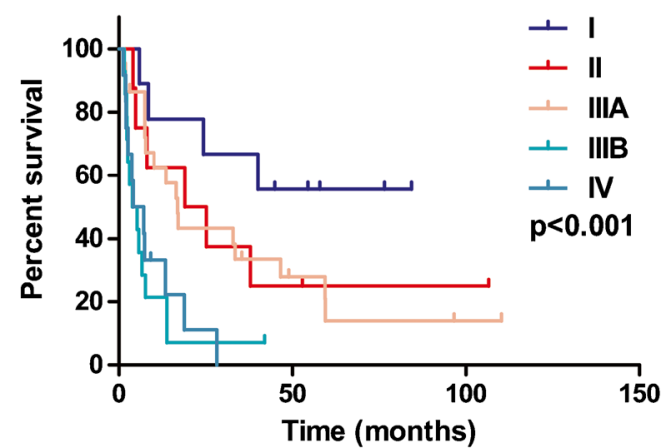

Fig. 1 Kaplan-Meier curves for OS of HCC patients with different TNM stages

$0.298,95 \%$ CI $0.150-0.592$; resection vs. ST: HR $0.105,95 \%$ CI $0.048-0.226, P=0.001)$ to be a predictor of OS.

To further investigate the relationship between the option of initial treatment and OS, we found that more patients with early or moderate stage received surgery, while a high proportion of the patients with moderate or advanced stage received TACE or ST $(P<0.001$, Fig. 3). These indicated that the uneven distribution of TNM stage may influence the OS of patients undergoing different types of initial treatment.

\section{Survival}

To exclude the influence of the different distribution of TNM stage on initial treatment subgroups, we compared the OS of patients at moderate or advanced stages that underwent different types of treatment. Kaplan-Meier analyses showed that, at the moderate stage, the median OS of patients who underwent resection was longer than that of patients who underwent other types of treatment (resection vs. TACE vs. ST: 38.0 vs. 13.6 vs. 1.8 months, $P<0.001$, Fig. $4 \mathrm{a})$. At the advanced stage, the OS of patients who underwent TACE was longer than that of patients who underwent ST (TACE vs. ST: 7.1 vs. 2.3 months, $P=0.045$, Fig. 4b).

\section{Discussion}

The present study demonstrated that C\&A with HCC tend to have advanced disease, and initial treatment allocation was found to be an independent prognostic factor. Resection could achieve long-term survival at the moderate stage compared with other types of treatment. Moreover, compared with ST, TACE could have beneficial effects on OS for the advanced stage of HCC.

Several differences with respect to clinical characteristics and outcomes between HCC in C\&A and that in adults have been reported. ${ }^{4,20}$ Our results identified HBV infection to be present in $81.5 \%$ of C\&A with HCC, which is similar to the prevalence of adult HCC in our hospital. ${ }^{21,22}$ In accordance with other studies, we found that HCC was more common in 
Table 2 Univariate and multivariate analyses of overall survival (OS)

\begin{tabular}{|c|c|c|c|c|}
\hline \multirow[t]{2}{*}{ Characteristic } & \multicolumn{2}{|l|}{ Univariate } & \multicolumn{2}{|l|}{ Multivariate } \\
\hline & HR $(95 \%$ CI) & $P$ & $\operatorname{HR}(95 \% \mathrm{CI})$ & $P$ \\
\hline \multicolumn{5}{|l|}{ Sex } \\
\hline Female & 1 (reference) & \multirow[t]{2}{*}{0.274} & & \\
\hline Male & $1.529(0.714-3.274)$ & & & \\
\hline \multicolumn{5}{|l|}{ HBV infection } \\
\hline No & 1 (reference) & \multirow[t]{2}{*}{0.306} & & \\
\hline Yes & $1.461(0.707-3.021)$ & & & \\
\hline \multicolumn{5}{|l|}{ Tumor number } \\
\hline Solitary & 1 (reference) & \multirow[t]{2}{*}{0.882} & & \\
\hline Multiple & $1.068(0.604-1.886)$ & & & \\
\hline \multicolumn{5}{|l|}{ TNM stage } \\
\hline Early & 1 (reference) & \multirow[t]{3}{*}{$<0.001$} & & \multirow[t]{3}{*}{0.072} \\
\hline Moderate & $2.420(0.835-7.014)$ & & & \\
\hline Advanced & $7.479(2.503-22.342)$ & & & \\
\hline \multicolumn{5}{|l|}{ Initial treatment } \\
\hline ST & 1 (reference) & \multirow[t]{3}{*}{$<0.001$} & 1 (reference) & \multirow[t]{3}{*}{$<0.001$} \\
\hline TACE & $0.298(0.150-0.592)$ & & $0.298(0.150-0.592)$ & \\
\hline Resection & $0.105(0.048-0.226)$ & & $0.105(0.048-0.226)$ & \\
\hline \multicolumn{5}{|c|}{ Distant metastasis } \\
\hline No & 1 (reference) & \multirow[t]{2}{*}{0.018} & & \multirow[t]{2}{*}{0.448} \\
\hline Yes & $2.360(1.156-4.815)$ & & & \\
\hline \multicolumn{5}{|c|}{ Portal vein tumor thrombus } \\
\hline No & 1 (reference) & \multirow[t]{2}{*}{0.001} & & \multirow[t]{2}{*}{0.184} \\
\hline Yes & $2.725(1.484-5.004)$ & & & \\
\hline \multicolumn{5}{|c|}{ Tumor diameter $(\mathrm{cm})$} \\
\hline$\leq 5$ & 1 (reference) & \multirow[t]{2}{*}{0.215} & & \\
\hline$>5$ & $1.912(0.687-5.323)$ & & & \\
\hline \multicolumn{5}{|l|}{$\mathrm{TBIL}(\mu \mathrm{mol} / \mathrm{L})$} \\
\hline$\leq 20.5$ & 1 (reference) & \multirow[t]{2}{*}{0.023} & & 0.944 \\
\hline$>20.5$ & $1.947(1.094-3.465)$ & & & \\
\hline AST (U/L) & & & & \\
\hline$\leq 45$ & 1 (reference) & 0.006 & & 0.786 \\
\hline$>45$ & $2.365(1.287-4.346)$ & & & \\
\hline $\operatorname{ALT}(\mathrm{U} / \mathrm{L})$ & & & & \\
\hline$\leq 40$ & 1 (reference) & 0.059 & & \\
\hline$>40$ & $1.702(0.979-2.959)$ & & & \\
\hline $\operatorname{ALB}(g / L)$ & & & & \\
\hline$\leq 35$ & 1 (reference) & 0.457 & & \\
\hline$>35$ & $0.676(0.242-1.893)$ & & & \\
\hline $\mathrm{AFP}(\mathrm{g} / \mathrm{L})$ & & & & \\
\hline$\leq 25$ & 1 (reference) & 0.606 & & \\
\hline$>25$ & $1.309(0.47-3.649)$ & & & \\
\hline
\end{tabular}

$H B V$ hepatitis B virus, $T N M$ tumor-node-metastasis, $S T$ supportive treatment, $T A C E$ transcatheter arterial chemoembolization, $T B I L$ total bilirubin, $A S T$ aspartate transaminase, $A L T$ alanine aminotransferase, $A L B$ albumin, $A F P$ alpha-fetoprotein males than in females $(4: 1) .^{3,5}$ AFP is a useful diagnostic marker for HCC, and roughly $50-70 \%$ of adults with $\mathrm{HCC}$ have increased levels of AFP, ${ }^{3,23}$ compared with $>90 \%$ in C\&A in our study. Moreover, some studies have suggested higher serum levels of AFP to be correlated with worse outcome in HCC. ${ }^{24-26}$ We showed that $81.5 \%$ of C\&A with $\mathrm{HCC}$ had AFP $>400 \mathrm{ng} / \mathrm{mL}$, which suggests that C\&A tend to present with more advanced disease compared with adults. However, we did not find a significant difference in OS between the two groups (AFP $>400$ vs. $\leq 400 \mathrm{ng}$ / 
Fig. 2 Univariate analyses of prognostic factors using KaplanMeier survival curves. a Early, moderate, or advanced stage. $\mathbf{b}$ ST, TACE, or resection. c TBIL $\leq 20.5$ or $>20.5 \mu \mathrm{mol} / \mathrm{L}$. d Metastasis: no or yes. e AST $\leq 45$ or $>45 \mathrm{U} / \mathrm{L}$. f Portal vein tumor thrombus: no or yes
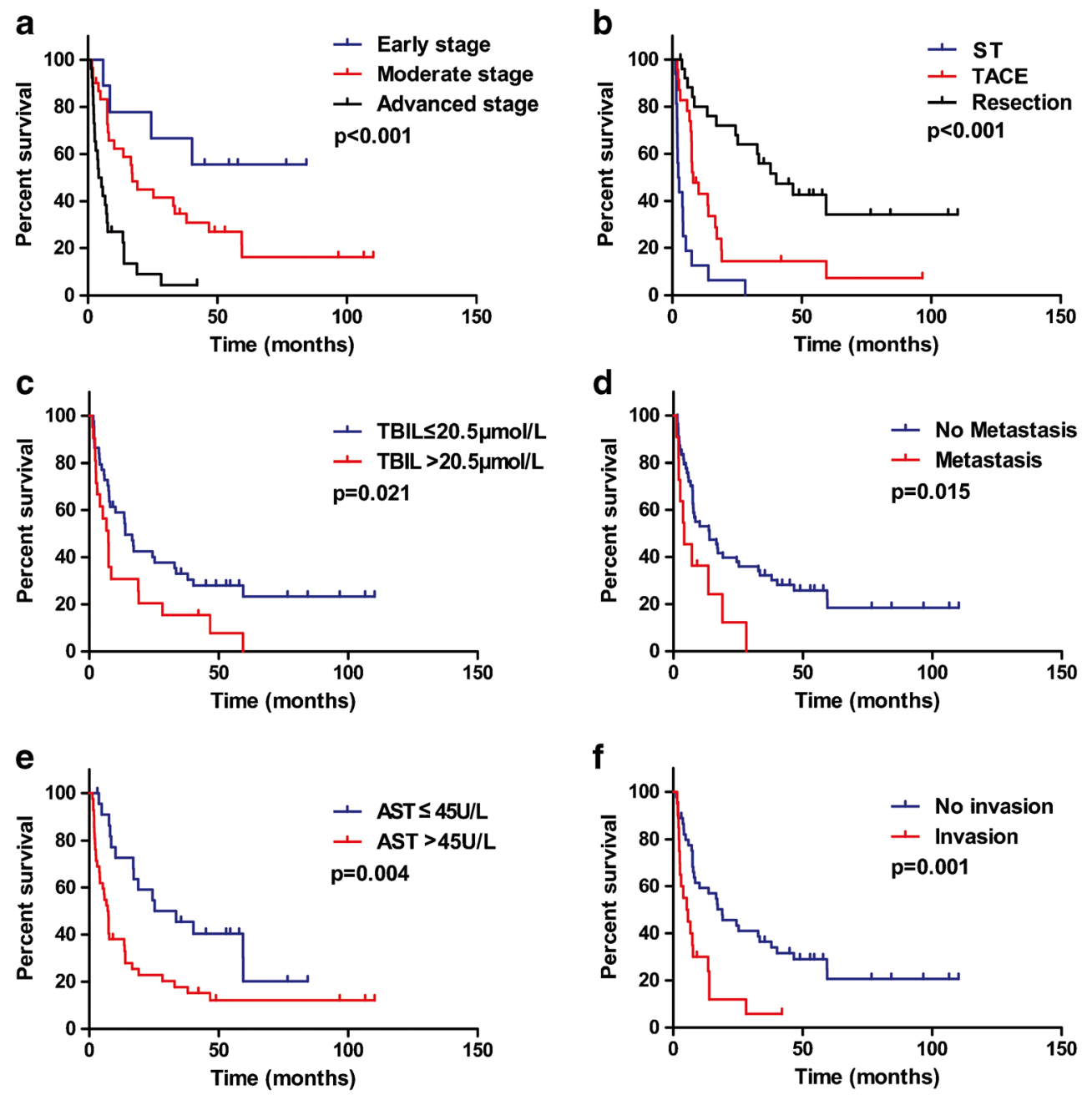
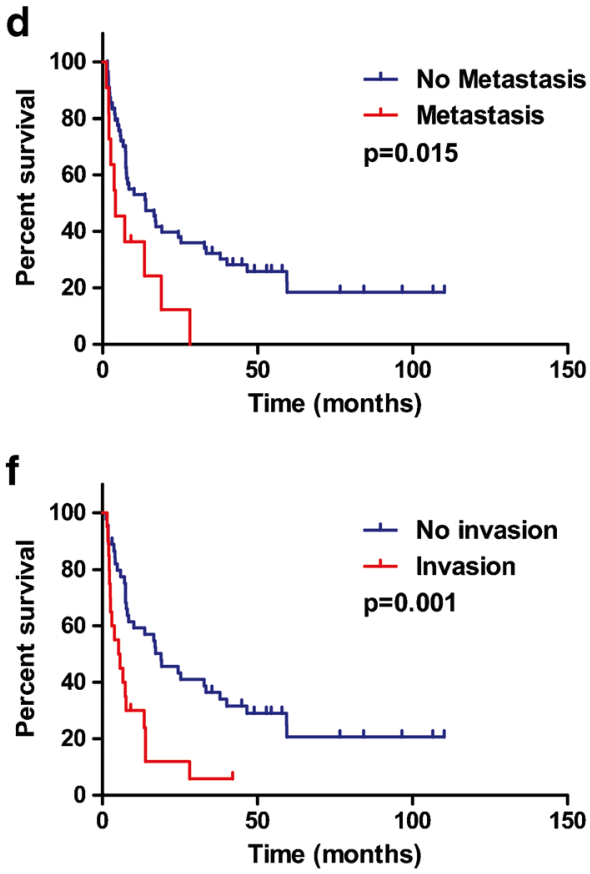

$\mathrm{mL}$; median OS 7.7 vs. 28.2 months, $P=0.075$ ), which might be due to the small sample size. Recent studies have shown serum levels of AFP to be associated with tumor diameter, ${ }^{27-29}$ as did our data $(r=0.261, P=0.035)$ (Fig. S1), with $58(89.2 \%)$ patients having a tumor diameter $>5 \mathrm{~cm}$ and $34(52.3 \%)$ patients having a tumor diameter $\geq 10 \mathrm{~cm}$. Moreover, multiple nodules were identified in 40 $(61.5 \%)$ C\&A patients. Recent studies have shown the prevalence of distant metastasis and tumor thrombus in the portal vein to be higher in C\&A than that in adults, which was correlated with worse outcomes. ${ }^{1,3 \cdot 4}$ We also showed that $11(16.9 \%)$ patients had distant metastasis and 20 (30.8\%) patients had tumor thrombus in the portal vein upon first hospital admission. Moreover, our findings showed that $\mathrm{HCC}$ in C\&A carried a dismal 5-year OS of $15.8 \%$, which is lower than that observed in adults. ${ }^{8,30}$ These findings suggest that $\mathrm{HCC}$ in $\mathrm{C} \& \mathrm{~A}$ tends to present with more advanced disease than that in adults.
Fig. 3 a Distribution of TNM stage for $\mathrm{HCC}$ in C\&A was different for different treatment types $\left(\chi^{2}<0.001\right)$. b Distribution of combined TNM stage for HCC in $\mathrm{C} \& \mathrm{~A}$ was different for different treatments $\left(\chi^{2}<0.001\right)$
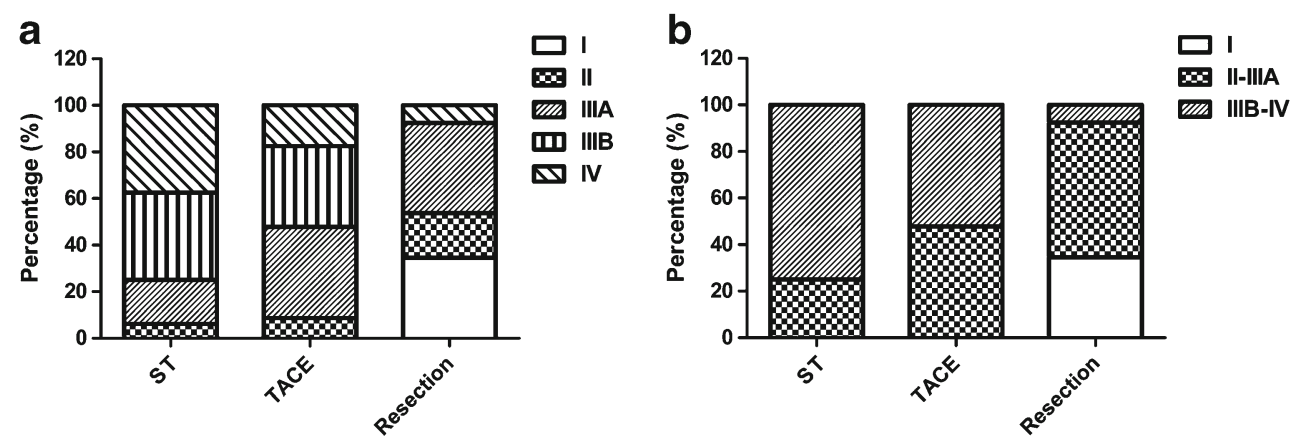


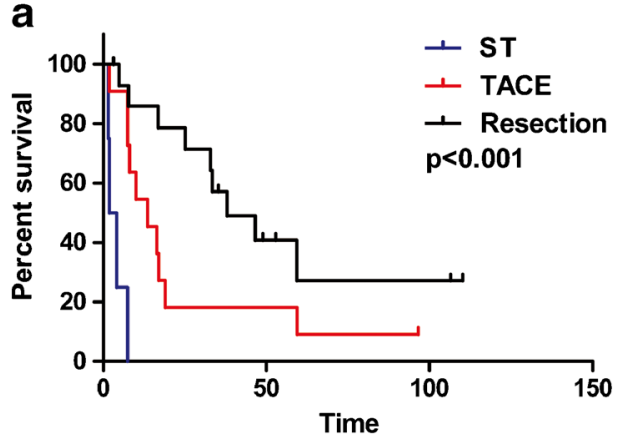

Fig. 4 a Kaplan-Meier curves for OS of HCC patients at the moderate stage. Median OS of patients who underwent resection was longer than that of patients who underwent TACE or ST $(38.0,13.6$, and 1.8 months, respectively, $P<0.001)$. b Kaplan-Meier curves for OS of HCC patients

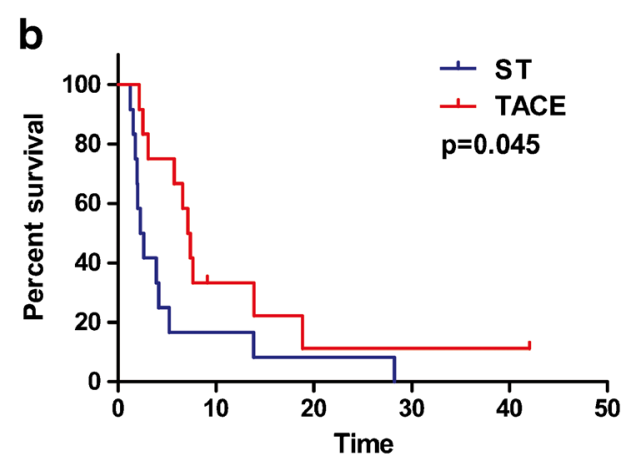

with advanced HCC. Median OS of patients who underwent TACE was longer than that of patients who underwent ST (7.1 vs. 2.3 months, $P=0.045)$. The black curve, red curve, and blue curve represent patients who underwent resection, TACE, and ST, respectively
Even though $\mathrm{HCC}$ in $\mathrm{C} \& \mathrm{~A}$ tends to be more malignant, treatment guidelines on HCC management are lacking., ${ }^{3,13}$ Using univariate and multivariate analyses, we identified initial treatment allocation to be an independent prognostic factor. Different types of initial treatment affected the prognosis of HCC in C\&A markedly, with the median survival for resection, TACE, and ST being 40.1, 8.0, and 2.3 months, respectively $(P<0.001$, Fig. 2 b). If stratified by TNM stage, moderate-stage patients who underwent resection had better outcome than those who underwent TACE or those who did have ST $(P<0.001$, Fig. 4a). For patients with advanced disease, those who underwent TACE had better outcome than those who did have ST $(P<0.05$, Fig. $4 b)$. TACE has been shown to improve survival for unresectable HCC in adults, ${ }^{31,32}$ but its role in C\&A with HCC is not known. ${ }^{3,17}$ Thus, our study showed that compared with ST, TACE might have an effect on unresectable HCC in C\&A. However, it should be noted that the difference in OS between ST and TACE might be based on differences in the clinical condition of patients due to the retrospective nature of the study, and prospective studies are needed to confirm those findings.

In the current retrospective study, none of the patients underwent liver transplantation. Some recent studies showed that liver transplantation might be an effective treatment option although the literature is sparse. The studies of Pham et al. and Malek et al. suggested that liver transplantation for HCC in C\&A could result in excellent long-term survival, even though the lesions were well outside the Milan and UCSF criteria. ${ }^{33,34}$ However, more studies are needed to verify transplantation as a therapeutic intervention for HCC in C\&A. Chemotherapy has little effect in improving survival. ${ }^{3,35}$ Preliminary results from the Pediatric Oncology Group (POG) study showed that a cisplatin-based chemotherapy regimen might benefit children with resectable $\mathrm{HCC}^{20}$ However, two subsequent prospective studies from the International Childhood
Liver Tumor Study Group (SIOPEL 2 and SIOPEL 3) found that intensification of platinum agents did not result in improved survival. ${ }^{36}$ Moreover, the data about ablative therapies and sorafenib in C\&A with HCC is lacking, which needs further study. At present, there is no standard clinical guideline for $\mathrm{HCC}$ in $\mathrm{C} \& \mathrm{~A}$, and more prospective studies should be conducted in the future.

In addition, two patients were found to have extrahepatic metastasis after laparotomy (one with a nodule in the gastric omentum and the other with a nodule in the diaphragm). When the tumors were removed successfully, the two patients died at 3.7 and 13.5 months, respectively.

Our study had three main limitations. First, this was a retrospective review of data collected from a single cancer center with a small sample size. Hence, we provided low-grade evidence for future therapy. ${ }^{37}$ Second, apart from one patient, the age of the other patients was 10-20 years old. Therefore, the efficacy of TACE in HCC patients under the age of 10 years must be evaluated further. Third, the efficacy of initial TACE therapy for patients with unresectable HCC might be skewed by subsequent treatments. Nevertheless, this can be deciphered by the better treatment response for initial TACE therapy because the subsequent treatments depended mostly on tumor burden and liver function. ${ }^{31}$

\section{Conclusions}

Compared with $\mathrm{HCC}$ in adults, $\mathrm{HCC}$ in C\&A tends to be more advanced, which results in worse survival in C\&A. Initial treatment allocation was found to be an independent prognostic factor for HCC in C\&A. Consistent with other studies, our study showed that resection is the recommended choice for early- and moderate-stage HCC when technically feasible. Moreover, we found that, compared with ST, TACE may benefit C\&A with moderate- and advanced-stage HCC. 
Acknowledgements We would like to thank ELIXIGEN company for English language editing.

Author contributions Juncheng Wang, Yize Mao, Xiangming Lao, and Shengping Li were responsible for the study's conceptualization; Juncheng Wang and Yize Mao for the formal analysis; Juncheng Wang, Yize Mao, Yongcheng Liu, Zhenxin Chen, Minshan Chen, Xiangming Lao, and Shengping Li for the investigation; Xiangming Lao and Shengping Li for data curation; Juncheng Wang and Yize Mao for the writing of the original draft; all authors for the writing, review, and editing; Juncheng Wang, Yize Mao, Yongcheng Liu, Zhenxin Chen, and Minshan Chen for the visualization; Xiangming Lao and Shengping Li for the supervision; and Xiangming Lao and Shengping Li for the project administration.

\section{Compliance with Ethical Standards}

Conflict of Interest The authors declare that they have no conflicts of interest.

\section{Funding Sources No specific funding was disclosed.}

Open Access This article is distributed under the terms of the Creative Commons Attribution 4.0 International License (http:// creativecommons.org/licenses/by/4.0/), which permits unrestricted use, distribution, and reproduction in any medium, provided you give appropriate credit to the original author(s) and the source, provide a link to the Creative Commons license, and indicate if changes were made.

\section{References}

1. Llovet JM, Zucman-Rossi J, Pikarsky E, Sangro B, Schwartz M, Sherman $\mathrm{M}$ et al. Hepatocellular carcinoma. Nature Reviews Disease Primers. 2016;2:16018. doi:10.1038/nrdp.2016.18.

2. Torre LA, Bray F, Siegel RL, Ferlay J, Lortet-Tieulent J, Jemal A. Global cancer statistics, 2012. CA: a Cancer Journal for Clinicians. 2015;65(2):87-108. doi:10.3322/caac.21262.

3. Kelly D, Sharif K, Brown RM, Morland B. Hepatocellular carcinoma in children. Clinics in Liver Disease. 2015;19(2):433-47. doi: 10.1016/j.cld.2015.01.010.

4. Zhang XF, Liu XM, Wei T, Liu C, Li MX, Long ZD et al. Clinical characteristics and outcome of hepatocellular carcinoma in children and adolescents. Pediatric Surgery International. 2013;29(8):76370. doi:10.1007/s00383-013-3334-4.

5. Hung GY, Horng JL, Yen HJ, Lee CY, Lin LY. Changing incidence patterns of hepatocellular carcinoma among age groups in Taiwan. Journal of Hepatology. 2015;63(6):1390-6. doi:10.1016/j.jhep. 2015.07.032

6. El-Serag HB. Hepatocellular carcinoma. The New England Journal of Medicine. 2011;365(12):1118-27. doi:10.1056/ NEJMra1001683.

7. McAteer JP, Goldin AB, Healey PJ, Gow KW. Hepatocellular carcinoma in children: epidemiology and the impact of regional lymphadenectomy on surgical outcomes. Journal of Pediatric Surgery. 2013;48(11):2194-201. doi:10.1016/j.jpedsurg.2013.05. 007.

8. Darbari A, Sabin KM, Shapiro CN, Schwarz KB. Epidemiology of primary hepatic malignancies in U.S. children. Hepatology (Baltimore, Md). 2003;38(3):560-6. doi:10.1053/jhep.2003.50375.

9. von Schweinitz D. Management of liver tumors in childhood. Seminars in Pediatric Surgery. 2006;15(1):17-24. doi:10.1053/j. sempedsurg.2005.11.004.
10. Hadzic N, Finegold MJ. Liver neoplasia in children. Clinics in Liver Disease. 2011;15(2):443-62, vii-x. doi:10.1016/j.cld.2011. 03.011.

11. McAteer JP, Goldin AB, Healey PJ, Gow KW. Surgical treatment of primary liver tumors in children: outcomes analysis of resection and transplantation in the SEER database. Pediatric Transplantation. 2013;17(8):744-50. doi:10.1111/petr.12144.

12. Hiyama E. Current therapeutic strategies for childhood hepatic malignant tumors. International Journal of Clinical Oncology. 2013;18(6):943-5. doi:10.1007/s10147-013-0607-9.

13. Allan BJ, Wang B, Davis JS, Parikh PP, Perez EA, Neville HL et al. A review of 218 pediatric cases of hepatocellular carcinoma. Journal of Pediatric Surgery. 2014;49(1):166-71; discussion 71. doi:10.1016/j.jpedsurg.2013.09.050.

14. Bruix J, Llovet JM, Castells A, Montana X, Bru C, Ayuso MC et al. Transarterial embolization versus symptomatic treatment in patients with advanced hepatocellular carcinoma: results of a randomized, controlled trial in a single institution. Hepatology (Baltimore, Md). 1998;27(6):1578-83. doi:10.1002/hep.510270617.

15. Lencioni R, de Baere T, Soulen MC, Rilling WS, Geschwind JH. Lipiodol transarterial chemoembolization for hepatocellular carcinoma: a systematic review of efficacy and safety data. Hepatology (Baltimore, Md). 2016. doi:10.1002/hep.28453.

16. Lee HS, Kim KM, Yoon JH, Lee TR, Suh KS, Lee KU et al. Therapeutic efficacy of transcatheter arterial chemoembolization as compared with hepatic resection in hepatocellular carcinoma patients with compensated liver function in a hepatitis B virusendemic area: a prospective cohort study. Journal of Clinical Oncology : official journal of the American Society of Clinical Oncology. 2002;20(22):4459-65.

17. Chen JC, Chen CC, Chen WJ, Lai HS, Hung WT, Lee PH. Hepatocellular carcinoma in children: clinical review and comparison with adult cases. Journal of pediatric surgery. 1998;33(9): $1350-4$.

18. Malogolowkin MH, Stanley P, Steele DA, Ortega JA. Feasibility and toxicity of chemoembolization for children with liver tumors. Journal of Clinical Oncology : official journal of the American Society of Clinical Oncology. 2000;18(6):1279-84.

19. Edge SB, Compton CC. The American Joint Committee on Cancer: the 7th edition of the AJCC cancer staging manual and the future of TNM. Annals of surgical oncology. 2010;17(6):1471-4. doi:10. 1245/s10434-010-0985-4.

20. Katzenstein HM, Krailo MD, Malogolowkin MH, Ortega JA, LiuMares W, Douglass EC et al. Hepatocellular carcinoma in children and adolescents: results from the Pediatric Oncology Group and the Children's Cancer Group intergroup study. Journal of Clinical Oncology : official journal of the American Society of Clinical Oncology. 2002;20(12):2789-97.

21. Xu L, Peng ZW, Chen MS, Shi M, Zhang YJ, Guo RP et al. Prognostic nomogram for patients with unresectable hepatocellular carcinoma after transcatheter arterial chemoembolization. Journal of hepatology. 2015;63(1):122-30. doi:10.1016/j.jhep.2015.02. 034.

22. Peng ZW, Zhang YJ, Chen MS, Xu L, Liang HH, Lin XJ et al. Radiofrequency ablation with or without transcatheter arterial chemoembolization in the treatment of hepatocellular carcinoma: a prospective randomized trial. Journal of Clinical Oncology : official journal of the American Society of Clinical Oncology. 2013;31(4):426-32. doi:10.1200/jco.2012.42.9936.

23. Benson AB, 3rd, Abrams TA, Ben-Josef E, Bloomston PM, Botha JF, Clary BM et al. NCCN clinical practice guidelines in oncology: hepatobiliary cancers. Journal of the National Comprehensive Cancer Network : JNCCN. 2009;7(4):350-91.

24. Ma WJ, Wang HY, Teng LS. Correlation analysis of preoperative serum alpha-fetoprotein (AFP) level and prognosis of 
hepatocellular carcinoma (HCC) after hepatectomy. World Journal of Surgical Oncology. 2013;11:212. doi:10.1186/1477-7819-11212.

25. Wong RJ, Ahmed A, Gish RG. Elevated alpha-fetoprotein: differential diagnosis - hepatocellular carcinoma and other disorders. Clinics in Liver Disease. 2015;19(2):309-23. doi:10.1016/j.cld. 2015.01.005.

26. Duvoux C, Roudot-Thoraval F, Decaens T, Pessione F, Badran H, Piardi T et al. Liver transplantation for hepatocellular carcinoma: a model including alpha-fetoprotein improves the performance of Milan criteria. Gastroenterology. 2012;143(4):986-94.e3; quiz e14-5. doi:10.1053/j.gastro.2012.05.052.

27. Abbasi A, Bhutto AR, Butt N, Munir SM. Corelation of serum alpha fetoprotein and tumor size in hepatocellular carcinoma. JPMA The Journal of the Pakistan Medical Association. 2012;62(1):33-6.

28. Toro A, Ardiri A, Mannino M, Arcerito MC, Mannino G, Palermo $\mathrm{F}$ et al. Effect of pre- and post-treatment alpha-fetoprotein levels and tumor size on survival of patients with hepatocellular carcinoma treated by resection, transarterial chemoembolization or radiofrequency ablation: a retrospective study. BMC Surgery. 2014;14: 40. doi:10.1186/1471-2482-14-40.

29. Liu C, Xiao GQ, Yan LN, Li B, Jiang L, Wen TF et al. Value of alpha-fetoprotein in association with clinicopathological features of hepatocellular carcinoma. World Journal of Gastroenterology : WJG. 2013;19(11):1811-9. doi:10.3748/wjg.v19.i11.1811.

30. Klintmalm GB. Liver transplantation for hepatocellular carcinoma: a registry report of the impact of tumor characteristics on outcome. Annals of Surgery. 1998;228(4):479-90.

31. Shi M, Lu LG, Fang WQ, Guo RP, Chen MS, Li Y et al. Roles played by chemolipiodolization and embolization in chemoembolization for hepatocellular carcinoma: single-blind, randomized trial. Journal of the National Cancer Institute. 2013;105(1):59-68. doi:10.1093/jnci/djs464.

32. Zhou ZG, Zheng XR, Zhou Q, Shi M, Zhang YJ, Guo RP et al. Impact of oral anti-hepatitis B therapy on the survival of patients with hepatocellular carcinoma initially treated with chemoembolization. Chin J Cancer. 2015;34(1):14. doi:10.1186/ s40880-015-0017-7.

33. Pham TA, Gallo AM, Concepcion W, Esquivel CO, Bonham CA. Effect of liver transplant on long-term disease-free survival in children with hepatoblastoma and hepatocellular cancer. JAMA Surgery. 2015;150(12):1150-8. doi:10.1001/jamasurg.2015.1847.

34. Malek MM, Shah SR, Atri P, Paredes JL, DiCicco LA, Sindhi R et al. Review of outcomes of primary liver cancers in children: our institutional experience with resection and transplantation. Surgery. 2010;148(4):778-82; discussion 82-4. doi:10.1016/j.surg.2010.07. 021.

35. Czauderna P, Mackinlay G, Perilongo G, Brown J, Shafford E, Aronson D et al. Hepatocellular carcinoma in children: results of the first prospective study of the International Society of Pediatric Oncology group. Journal of Clinical Oncology : official journal of the American Society of Clinical Oncology. 2002;20(12):2798804.

36. Murawski M, Weeda VB, Maibach R, Morland B, Roebuck DJ, Zimmerman A et al. Hepatocellular carcinoma in children: does modified platinum- and doxorubicin-based chemotherapy increase tumor resectability and change outcome? Lessons learned from the SIOPEL 2 and 3 studies. Journal of Clinical Oncology : official journal of the American Society of Clinical Oncology. 2016;34(10):1050-6. doi:10.1200/jco.2014.60.2250.

37. Koh C, Zhao X, Samala N, Sakiani S, Liang TJ, Talwalkar JA. AASLD clinical practice guidelines: a critical review of scientific evidence and evolving recommendations. Hepatology (Baltimore, Md). 2013;58(6):2142-52. doi:10.1002/hep.26578. 